\title{
Bodo Möller sites under new management
}

The speciality chemicals expert Lionel Breuilly has recently been appointed managing director of the French and Benelux subsidiaries of the Bodo Möller Chemie Group.

Lionel Breuilly has more than 20 years' experience in management in the fields of speciality chemicals and new materials. After completing a chemistry degree and graduating from the famous INSEAD business school, he spent more than seven years in leading sales and marketing positions for the French subsidiary of the 3M technology group and eleven years making a major contribution to strategy, marketing, project management and global growth at Huntsman.
Most recently he was employed by the consulting company Future Materials Group in London, where he was responsible for providing strategic consultancy to many international organisations.

In France and the Benelux countries, the main focus of the Bodo Möller Chemie Group is on professional adhesive systems based on epoxy resins, polyurethanes and methyl methacrylates from the manufacturers Dow Automotive and Huntsman Advanced Materials. Targeted development of the field of composites is also planned in all four countries under the management of Lionel Breuilly.

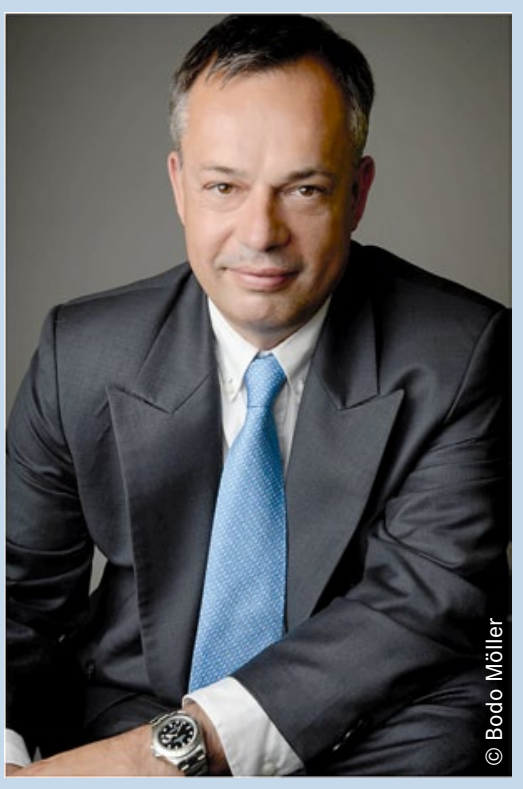

Lionel Breuilly, new managing director of the Bodo Möller sites in France and the Benelux countries.

\section{Bayer opens an innovation hub in Shanghai}

B ayer MaterialScience has opened a regional innovation hub for the Asia Pacific region in the city of Shanghai in China. More than $200 \mathrm{ex}^{-}$ perts will be employed at the hub to develop innovative applications for high-performance plastics, foams and coatings in key sectors such as mobility, construction, IT and renewable energy. They will work in close cooperation with external scientists, suppliers and customers. The new hub, which is located at the company's existing Polymer Research \& Development Centre (PRDC), will provide support for other innovation facilities across the region. The new centre is expected to attract local talent and enhance knowledge-building and transfer. Employees will work in international teams which will include colleagues from R\&D centres in Europe and North America. The innovation hub will be supported by a net-

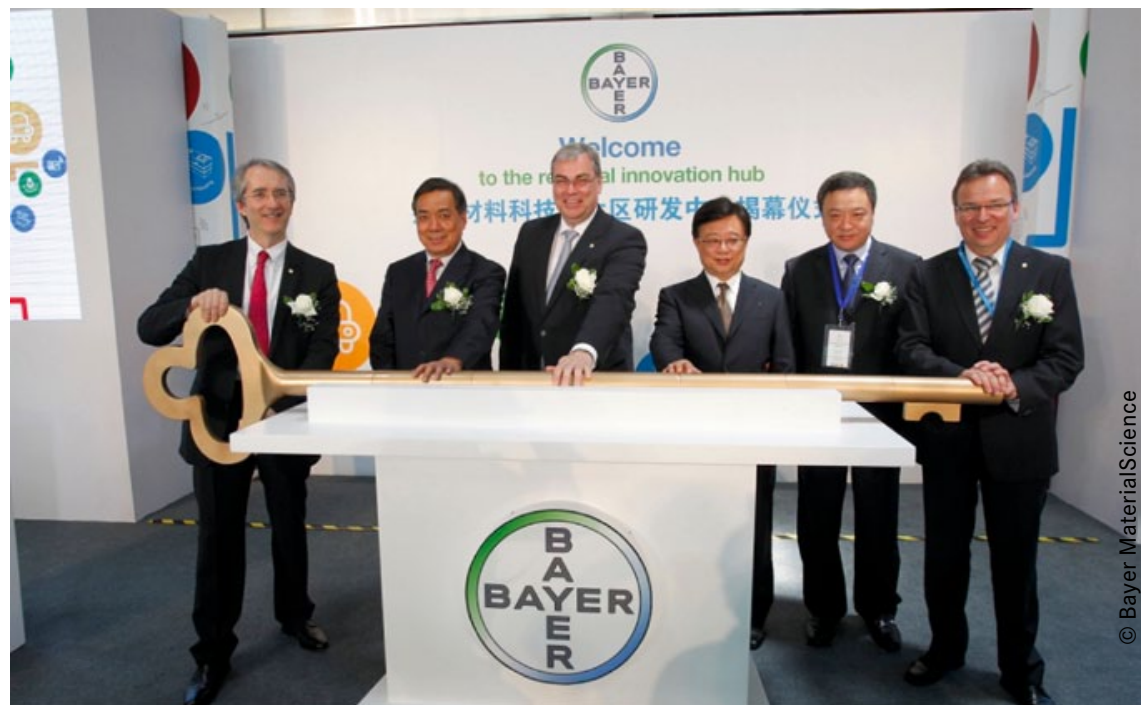

Opening the innovation hub in Shanghai: Patrick Thomas, CEO of Bayer MaterialScience (left), with officials from local authorities and other institutions as well as representatives from the Bayer Group.

work of production sites in the Asia Pacific region. The largest of these are in Shanghai, Map Ta Phut in Thailand and Niihama in Japan.
Asia Pacific is among the strongest growth regions for Bayer MaterialScience and accounted for more than one quarter of total sales in 2012. 